\title{
Aprendiendo ciencia con Godzilla
}

Claudia Sánchez Arce

\section{Resumen}

El presente artículo propone el aprovechamiento de la ciencia ficción y la sci-fi como motivación para el aprendizaje de la ciencia en la educación básica y media superior, mediante una estrategia de diálogo entre las inexactas concepciones científico-ficcionales y las correspondientes enunciaciones científicas académicamente aceptadas.

Palabras clave: ciencia ficción, sci-fi, ciencia, educación, novum, extrañamiento cognitivo.

\section{LEARN SCIENCE WITH GODZILLA}

\section{Abstract}

The present essay proposes the use of science fiction and sci-fi as a motivation for the learning of science in elementary, middle and high school, through strategies of dialogue between inaccurate scientific conceptions of fiction and corresponding academically accepted scientific statements.

Keywords: science fiction, sci-fi, science, education, novum, cognitive estrangement. 


\section{Claudia Sánchez Arce}

Profesora de educación primaria por parte de la Escuela Normal No. 1 del Estado de México; licenciada en Letras Latinoamericanas y maestra en Estudios Latinoamericanos por parte de la Facultad de Humanidades de la Universidad Autónoma del Estado de México. Desde 1985 ha trabajado como profesora estatal en primaria; subdirectora y orientadora, en secundaria; catedrática de preparatoria y normal; asesora profesional para docentes en servicio; auxiliar y coordinadora de Diseño Gráfico e Impresión. Desde 1993 es la responsable directa de la unificación de la imagen institucional en publicaciones y todo tipo de impresos en la sección de Diseño Gráfico e Impresión. Actualmente es responsable de esta misma sección, y, desde 1997, corresponsable del Proyecto de Producción Editorial de la Normal para Profesores.

Vinculado a su profesión, ha participado en innumerables ocasiones como jurado en concursos, dictaminadora en foros, asesorías e impartición de cursos y talleres, así como colaboradora en diversos proyectos, del que se destaca el Proyecto de Asesoría para la Certificación de la Licenciatura en Pedagogía-Ciencias de la Educación. En el campo de la cultura, ha dirigido el suplemento cultural Ocho días del ocho del diario Ocho columnas (1989-1991). Ha sido guionista de radio y televisión para los programas de la Comisión Estatal para el Fomento del Uso Correcto del Lenguaje (1993).

También en 1992 recibió la medalla y diploma del Comité los Mejores Estudiantes de México, concedida por el CONACYT, el Diario de México y la ANUIES. Ha publicado, gracias a la UAEM, su libro Los temas de la ciencia ficción en Trafalgar (1993). 


\section{Introducción}

Nací en 1965, cuando la ciencia comenzaba a rebasar los postulados de las películas de ciencia ficción y fui joven en la década de los ochenta, cuando empezaba a volverse nostálgica. En las dos últimas décadas ha habido un florecimiento de la ciencia ficción, la fantasía y el terror en los medios de comunicación, sobre todo en el cine y la televisión, lo que incluye la animación, gracias a los desarrollos digitales. En estas incontables ficciones suelen prevalecer postulados científicos no siempre correctos. La generación de fans a la que pertenezco aprendió ciencia de manera intensa en la literatura y la televisión, algo de lo que nos enorgullecíamos. Sin embargo, al ser espectadora acrítica de los productos televisivos, más tarde me percaté de haber aprendido una serie de conceptos erróneos acerca de la realidad y del entendimiento más certero de la misma, del discurso científico subyacente.

Umberto Eco en su libro Apocalípticos e

El reto del educador, sin embargo, radica en interaccionar con las obras que prevalecen en el gusto de los niños y los jóvenes, y que carecen de precisión conceptual o científica. integrados (1984) afirma que la ciencia ficción, así como otros productos de la cultura popular suelen convertirse en termómetros de las temáticas sociales en discusión. Basta mirar aquellas series y películas que nos fascinaban para entender que esto es real. Más que un ensayo sobre el futuro, la vieja ciencia ficción parece un espejo de la sociedad donde surgió, como todo discurso humano. No se precisa una mente tan aguzada como la de Eco para entender que la actual proliferación de zombis y vampiros da cuenta de los temores colectivos de las nuevas y aun de las viejas generaciones. Como docente de profesores normalistas, sin embargo, descubrir que las películas y series de fantasía, sci-fi, terror y policiacas son el semillero de las concepciones científicas de nuestros futuros profesores resulta una cuestión digna de estudio.

Al pertenecer a la cultura popular, la ciencia ficción ha sido omnipresente en los medios de comunicación de masas desde su aparición (ya sea que su origen se remonte al siglo xIx o se le considere más reciente, en la primera mitad del siglo xx), y ha sido responsable de la popularización de temas científicos. Como aficionada, desarrollé gran parte del aprendizaje no escolarizado de ciencia en los productos del género. Leer ciencia ficción y consumir sci-fi (desde filmes hasta seriales, pasando por anuncios comerciales y música) me permitió conocer los temas que interesaban a la sociedad occidental en el siglo xx y que, se anticipaba, serían determinantes en la prospectiva adivinada para el xxı, tal como señala Eco. Debo señalar, sin embargo, que el siglo xxı ha rebasado los discursos futuristas de la ciencia ficción. 
Los productos para consumo del público lector y espectador, sin embargo, presentan un doble filo, pues al tiempo que postulan los temas relevantes, álgidos y perentorios de las sociedades modernas, y los ubican en el territorio del debate, también mantienen la capacidad de normar criterios y formar opiniones, las cuales no siempre mantienen su fundamento en la ciencia. El público adulto que consume estos productos está avisado de su naturaleza ficcional y mantiene una sana distancia que le permite gozar el espectáculo, suspenden la incredulidad, pero la restauran una vez termina el espectáculo. No ocurre esto con niños y adolescentes, quienes aún desconocen que para mirar una ficción deben suspender la desconfianza en favor del disfrute y el entretenimiento; pero a la vez, deben retirarse del espectáculo sin creer todo lo que se diga en él como si fuera verdadero, sino sólo verosímil, creíble, sólo verificable dentro de ese mundo ficcional. A los niños les faltan las herramientas para precaverse contra ideas carentes de fundamento. Como maestra de educación básica, media superior y normal, he sido testigo de los conceptos erróneos que manejan los jóvenes profesores, así como los niños y jóvenes, una vez que el espectáculo acaba. Por ejemplo, en 1994, cuando el cometa Shoemaker-Levy 9 colisionó con Júpiter, algunos niños preguntaron a mis alumnos normalistas durante las prácticas si los astronautas corrían algún riesgo con el choque, aun cuando en ese momento no había ningún ser humano en el espacio y la distancia hasta el evento es inmensamente grande (ver imagen 1).

\section{$\equiv \quad$ OAdo asond de 2019 \\ NACIONAL ARCHIVO \\ 1994: Se impactan fragmentos del cometa Shoemaker-Levy 9 en Júpiter}

Un día como hoy...

EL. SIGLO DE TORREÓN lunes 16 do julio 2012, actualizada 8:31 pm

Imagen 1. Captura de pantalla del diario El Siglo de Torreón, sobre el impacto del Shoemaker-Levy 9, en julio de 1994. Esta noticia

fue ampliamente comentada en los noticieros y en la naciente internet; también fue un evento que preocupó a los niños de primaria (Archivo Nacional, 2012).

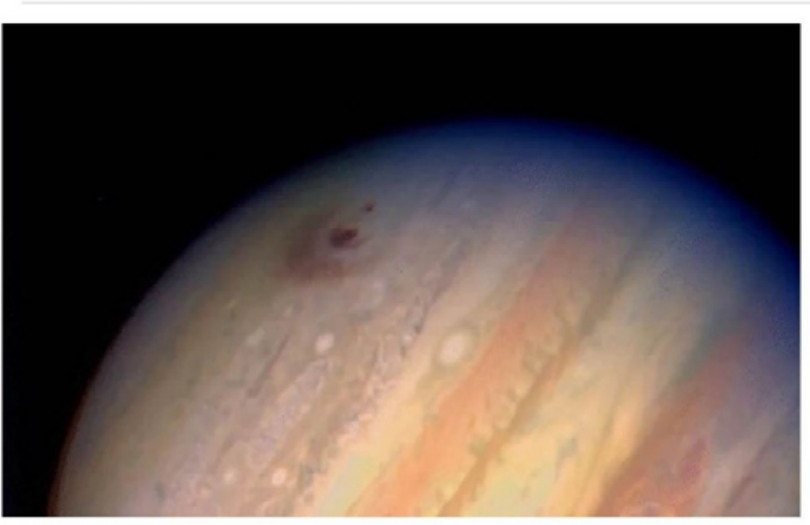


1 Para efectos de este artículo se denomina ciencia ficción a la versión escrita, la literaria; mientras que sus variantes (todo objeto no literario que recupere la tematología del género: cine, radio, cómics, artes plásticas, anuncios, música y otros) se denominan sci-fi (véase Pringle, 1991).

2 Se denomina tematología a la "rama de la literatura comparada que estudia aquella dimensión abstracta de la literatura que son los materiales de que está hecha, así como sus transformaciones y actualizaciones; estudia, en otras palabras, los temas y motivos que, como filtros, seleccionan, orientan e informan el proceso de producción de los textos literarios" (Pimentel, 1993,

pág. 215).
Como objeto de conocimiento, ni la sci-fi ni sus reseñas se preocupan de la percepción de la ciencia entre los jóvenes receptores del género, debido a que su objetivo es promover el ingreso en taquilla; sin embargo, la ausencia de precisión científica de estos productos se convierte en un asunto relevante para los educadores. Lejos de ser movidos por una manía que busque la corrección, los docentes estamos motivados por una genuina preocupación cuando reconocemos que el poderoso discurso de los productos de entretenimiento implanta ideas que son difíciles de erradicar o enderezar en las mentes jóvenes: se precisan variadas experiencias escolares para formar en ellos la distinción entre los géneros ficcionales y el discurso de las ciencias aceptadas. Pero a veces basta una película para echar abajo ese trabajo.

En este escrito, procuraré establecer una definición sobre ciencia ficción, desde mi perspectiva como fanática del género y profesora normalista; haré mención de un estudio que verifica las concepciones equivocadas sobre ciencia que los estudiantes de educación media superior adquieren a través del cine del género, y proporcionaré una estrategia para aprovechar un ícono del mismo, Godzilla, en la discusión escolarizada sobre ciencia.

Afirmo, sin embargo, que los fanáticos de cualquier ficción tenemos la capacidad para distinguir el discurso de ésta del de la ciencia, y que disfrutamos como corresponde las cintas y los libros, sin prejuicios. Es la maestra en mí la que se preocupa cuando un futuro profesor cuela en medio de la clase un concepto equivocado. Ésta es la corrección científica que me preocupa.

\section{Ciencia ficción}

Lo primero que nos atrae a los fanáticos de la ciencia ficción es el tema, la más visible de sus características. En el ámbito de la tematología ${ }^{2}$ genérica entran textos, ya sea novelas, series, filmes o cómics, que pudieran parecer literatura de ciencia ficción, pero no lo son. Es decir, un robot o una nave espacial son insuficientes como señal genérica, si éstos carecen de un postulado teórico que los sustente. Reducir el estudio de la ciencia ficción a la tradición que establece temasy motivos típicos como elviaje espacial, la batalla intergaláctica, los bestiarios extraterrestres o los poderes paranormales, conduce a meter en el mismo saco a productos donde el discurso de la ciencia aceptada es acuciosamente presentado, junto a otros que contienen imprecisiones científicas, aunque sean encomiables. Algunos usan los temas y motivos típicos con fines diversos a la literatura de ideas que es la ciencia ficción.

No es por mera afectación que hago esta distinción, sino por una razón de tiempo escolar. El estudio de una obra elegida por los estudiantes de básica y media merma el tiempo que puede dedicarse a estudiar obras de calidad, sobre todo cuando reconocemos que los jóvenes consumen esas ficciones asiduamente fuera del aula, por lo que es innecesario introducirlas al temario de la clase (ver videos 1 y 2). Digamos que en verdad el baremo de la calidad 
Videos 1 y 2. Tráiler de Guerreros del futuro (James Franco, Bruce Thierry Cheung, 2018; https://youtu.be/ cDisMuvdZoA). Ejemplo de sci-fi fílmica que recurre a imágenes de acción y violencia como recurso expresivo, en contraste con otras películas de ciencia ficción, que se basan en el argumento, como es el caso de la argentina Un hombre mirando al Sudeste (Eliseo Subiela, 1987; https://youtu.be/sOfLcuXNthY). En ciencia ficción el "¿qué pasaría si...?" es muy rico y atrayente, pues es la base de la especulación científica. En el filme de Subiela la duda es si ya ha llegado un visitante de otro mundo a la Tierra, o si sólo se trata de un alienado mental. no radica sólo en la escritura sobre los temas típicos de la ciencia ficción, sino también en la exigencia cognitiva, tanto en el escritor como en el lector. Aunque los maestros no debiéramos pretender obtener algo más que disfrute en la contemplación de un espectáculo, al menos deberíamos acompañar al alumno para ayudarle a desentrañar los errores conceptuales que contenga.
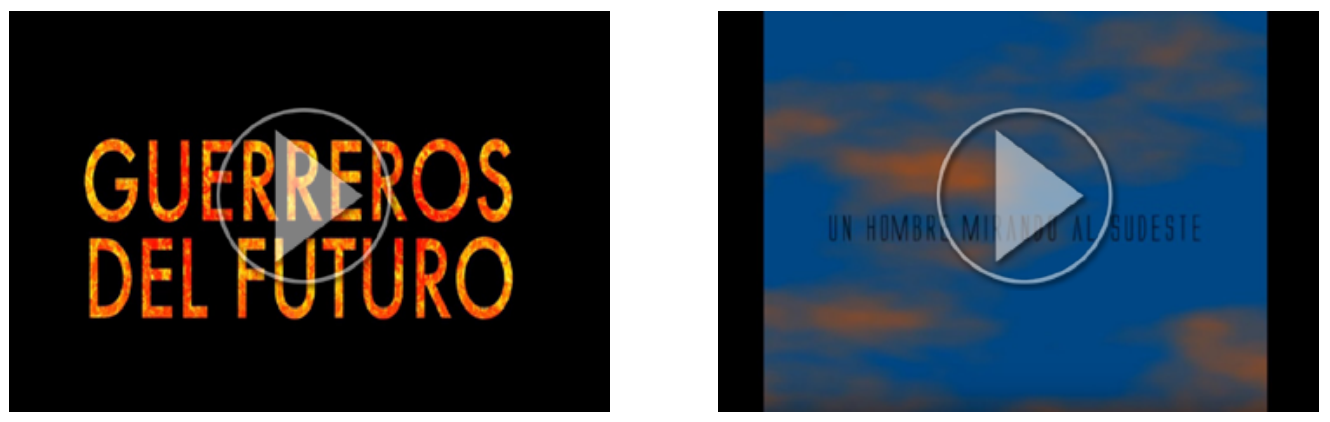

Una vez que el aficionado a la ciencia ficción supera el encanto de la tradición temática, se aboca a elegir entre la creciente oferta aquellas obras que se diferencian de entre la multitud por alguna característica en particular. En parte, este crecimiento del lector y del espectador del género transita hacia los mecanismos que producen la ficción narrativa. En este aspecto relacionado con la hechura de la ciencia ficción, el elemento recurrente (fuera de los temas) es el extrañamiento cognitivo, término acuñado por Darko Suvin. Para este estudioso, la ficción científica se caracteriza por presentar un cronotopo (un tiempo y lugar característicos), que se desprende o separa en algún grado del mundo cero de la realidad del escritor, del momento de la creación o del tiempo del lector. Es decir, el contexto en el que se realiza la escritura y la lectura del texto constituye el mundo cero de donde se desprende la narrativa. Obviamente esto sucede en toda ficción, pues el escritor suele hablar de su tiempo y su lugar, o modelar otros afincados en lo conocido, incluso en aquellas narraciones que pudieran parecer más apegadas a la realidad, como pudiera ser el caso de una novela histórica. En el caso de la ciencia ficción ese desprendimiento, ese alejamiento de lo conocido, se realiza desde la perspectiva estricta del conocimiento y los métodos científicos validados por la comunidad académica en el horizonte cero de la escritura. Como productos de su tiempo, ni la ciencia ficción ni la ciencia se estancan en ciertos estándares o parámetros, porque ambas están en constante desarrollo, donde no hay verdades establecidas ni fijas, a lo más, presentan conocimientos validados y formas estéticas novedosas.

Para conseguir delimitar en este punto a la ciencia ficción, es imprescindible acudir a Darko Suvin (1984), el más reconocido estudioso del género, quien lo define como literatura del extrañamiento cognitivo signado por un novum o novedad científica. Es decir, el escritor asume, además de la tradición temática (mundos alternos, otredad, máquina, tiempo), el requerimiento de que su ficción se desplace en un mínimo grado del mundo cero, para realizar mediante el artificio 
de las palabras el necesario extrañamiento requerido por cualquier ficción, pero lo hace fundamentalmente con el apoyo de la cognición -preferente pero no excluyentemente científica-, usando un novum o novedad como tema o como motivo que impulse el desarrollo de la trama, y sin el cual, éste no se produciría. Las ficciones que contestan al "qué pasaría si...", por ejemplo, se lograra alcanzar la velocidad de la luz, pueden recurrir a una nave o a un artilugio que rompa el límite físico, pero no siempre se preocupan por los efectos de la relatividad. En la narrativa científica aparecieron las naves espaciales, las guerras bacteriológicas, los satélites artificiales y los aparatos de comunicación personalizados, mucho antes que en la realidad de este mundo, pero su utilización en la ficción no se limitó a mostrarlos, también se especuló sobre sus efectos sociales e individuales.

En mi opinión, el novum ofrece al lector lego tanto como al aficionado un elemento formal o de fondo inexplorado o innovador en el ámbito de la tradición genérica y en el más amplio de la cognición humana, sin rebasar los límites aceptados por el estado de la ciencia actual. Existen películas acuciosamente cercanas a los conceptos científicos que son ejemplo de este doble encuentro entre el tema y el novum: 2001 (Stanley Kubrick, 1968), Contacto (Robert Zemeckis, 1997), Interestelar (Christopher Nolan, 2014), The Martian (Ridley Scott, 2015), La llegada (Denis Villeneuve, 2016) y Gattaca (Andrew Niccol, 1997). Todas ellas han sido asesoradas o escritas por científicos y se sustentan en una novedad o postulado científico: el contacto con inteligencias diversas en estructuras mentales y de comunicación, la vida en gravedad cero o baja, o la sobrevivencia humana en otros ecosistemas. El reto del educador, sin embargo, radica en interaccionar con las obras que prevalecen en el gusto de los niños y los jóvenes, y que carecen de precisión conceptual o científica.

\section{Efectos de la sci-fi y la ciencia ficción popular}

El uso de una novedad o novum, o sea, de un conocimiento científico, aplicado a la especulación narrativa, es el soporte relevante en la ciencia ficción. Ahí radica la potencia educativa del género para la enseñanza de la ciencia. No se trata de un afán normativo o didáctico el que norma la delimitación genérica ofrecida por Suvin, porque finalmente la CF popular, alentada por sus fanáticos y sus noveles escritores, demuestra una fortaleza indiferente a cualquier restricción impuesta por la crítica. Sin embargo, el docente debe hallar las herramientas que le permitan identificar las obras dignas de estudio escolarizado de entre la amplia producción que ofrece el mercado.

El problema de lasci-fien general es que sus mecanismos de entretenimiento son tan poderosos, y han superado de tal manera las reticencias del gran público, que los temas de la ciencia ficción han escapado del reducto de los fandoms (conjunto de aficionados) para volverse parte de la cultura popular, lo que reporta mayor provecho para la industria del entretenimiento. Pero este arribo a la popularidad no ha llegado aparejado con una acentuación en la precisión de la ciencia empleada. Por tanto, si crecimos alimentándonos de la 
3 The Science \& Entertainment Exchange (The Exchange) es un programa de la Academia Nacional de Ciencias (NAS [por sus siglas en inglés]) que conecta a los profesionales de la industria del entretenimiento con los mejores científicos e ingenieros para crear una sinergia entre la ciencia formal y las atractivas historias que presentan tanto el cine como la programación televisiva.

Desde una verificación rápida de datos hasta una sesión informativa especial, The Exchange brinda acceso

rápido y fácil a expertos de todas las disciplinas científicas. El objetivo de The Exchange es utilizar el vehículo de los medios de entretenimiento populares para entregar mensajes a veces sutiles, pero no obstante poderosos, sobre la ciencia. (National Academy of Sciences, 2016, traducción propia). literatura de ciencia ficción, probablemente su lectura y contemplación despertó nuestra sed por el conocimiento. En cambio, la actual tendencia de los medios es ofrecer al gran público productos que toman a los temas y a la ciencia como mero pretexto para estimular otros apetitos, como la aventura, el romance, la intriga, el miedo o el morbo, con muy poca corrección en la factura científica.

Una muestra de estas producciones la podemos encontrar en las ficciones de mundos alternativos, con empleo de una máquina o simplemente con el recurso del mundo paralelo, pero donde no se consideran las imposibilidades científicas del evento. Ocurre con los space western (en vez de indios, aliens), space opera (en lugar de imperios terrestres, imperios espaciales) y viajes temporales (donde la diversidad lingüística es soslayada), usados para alejar al lector de lo cotidiano, exclusivamente con fines de entretenimiento. En ocasiones el mismo argumento se usa para ficciones más terrenales, es decir, da lo mismo desarrollar la narración en el pueblo de al lado que hacerlo en el espacio sideral.

El problema es que algunas falsas afirmaciones postuladas en tales ficciones pueden trascender y ser consideradas como parte del discurso de la ciencia. Y como nacen dentro de poderosos vehículos de entretenimiento, mantienen un público que se renueva a cada generación. En ocasiones dicho público carece de una formación que le permita hacer una distinción nítida entre la realidad y la ficción. Tan importante se considera el vínculo entre las ciencias y el entretenimiento, que en los Estados Unidos existe desde noviembre de 2008 el programa de Intercambio de Ciencia y Entretenimiento. ${ }^{3}$

Con este recurso el cine acude a los científicos para hacer sus ficciones más plausibles, dejando así de abusar de la ciencia, como ha hecho desde su nacimiento como arte, para, en cambio, enseñar algo de ella a sus espectadores.

\section{Ciencia ficción y educación}

¿Cómo afecta a la educación este doble extremo del discurso de la ciencia en relación con el discurso del entretenimiento? Pues que, en muchos sentidos, pareciera que los medios educan sobre ciencia con más éxito que la escuela. En el estudio "The Impact of Science Fiction Film on Student Understanding of Science", el abstract resume:

Los investigadores que se dedican a estudiar la comprensión pública de la ciencia han argumentado que la ficción presentada en cine y televisión es particularmente eficaz a la hora de difuminar la distinción entre realidad y ficción. El fundamento de dichos estudios radica en la idea de que para enseñar la ciencia de manera efectiva, los educadores deben comprender la manera como la cultura popular influye en la percepción y comprensión de la ciencia por parte de sus estudiantes. Usando métodos de investigación naturalista en diversas preparatorias [High Schoo/], encontramos que los estudiantes que vieron una película popular de ciencia ficción, El núcleo [The Core, Jon Amiel, 2003], manifestaron tergiversaciones sobre conceptos referidos a las ciencias de la tierra, en comparación con aquellos 
estudiantes que no vieron la película. Encontramos que una sola visualización de una película de ciencia ficción puede impactar negativamente las ideas de los estudiantes con respecto a los fenómenos científicos. Específicamente, encontramos que la película aprovechó la autoridad científica del personaje principal, junto con explicaciones científicamente correctas de algunas ciencias de la tierra básicas, para crear una serie de ideas plausibles, aunque no científicas, que tuvieran sentido para los estudiantes (Barnett, Wagner, Gatling, Anderson, y Kafka, 2006, pág. 179).

Por lo que, sin mayor abundamiento, se señala que es más poderosa una explicación plausible de un personaje fílmico (un científico verosímil), que todo un curso sobre la materia, en la mente de los jóvenes, y que el cine tiene la tendencia a borrar los límites entre los hechos y la ficción. Este interesante estudio concluye que el problema radica en considerar los efectos de la ciencia ficción en el conocimiento universitario de la ciencia sólo en el análisis de la percepción de la ciencia, obviando el estudio de la percepción del cine. Por lo que sugiere analizar las concepciones científicas afectadas por la ficción, ya que hasta ahora el interés de los estudiosos se ha centrado en la forma cómo la ciencia ficción beneficia al campo de la ciencia y las vocaciones científicas: la temprana introducción de los jóvenes a los productos de la sci-fi puede conducir al interés por la ciencia, efecto que es aprovechado por algunas escuelas para conducir a un mayor interés por las carreras científicas. Este efecto positivo, que se nota en el gran número de científicos aficionados a la ciencia ficción, sin embargo, es contrarrestado por las incontables personas fuera del campo profesional, que mantienen concepciones incorrectas sobre temas de ciencia y pensamiento científico como consecuencia de confiar en el discurso del cine. Por ello el estudio "Impacto de las películas de ciencia ficción en el entendimiento de la ciencia por parte de los estudiantes" (Barnett, M., Wagner, H., Gatling, A., Anderson, J., y Kafka, A., 2006) concluye:

Las películas de ciencia ficción tienen la capacidad de captar la atención y la imaginación de los estudiantes, y las investigaciones han demostrado que en general el interés del público en la ciencia a menudo aumenta cuando se expone a la ciencia en la televisión y en las películas. Por lo tanto, en lugar de evitar exhibir películas de ciencia ficción en las escuelas, puede ser una mejor estrategia involucrar a los estudiantes en la crítica de las mismas. Tal enfoque puede hacer que ellos reflexionen no solo sobre la ciencia tal como se presenta en la película, sino también sobre sus propias ideas y cómo se comparan éstas con las presentadas en la pantalla. Sin embargo, para hacer esto de manera efectiva, como educadores científicos y docentes, es importante que proporcionemos a los profesores las habilidades y experiencias necesarias para evaluar la ciencia tal como se presenta en las películas. Sobre la base de este trabajo, hemos instituido un nuevo proyecto dentro de nuestros cursos introductorios de ciencias para los profesores en formación. Es decir, les pedimos a los profesores en formación que elijan películas de una lista y evalúen la precisión científica y la plausibilidad de la ciencia tal como se presenta en el caso particular. Creemos que tales experiencias pueden facilitar que los futuros maestros ayuden a sus estudiantes a evaluar críticamente tanto la ciencia buena como la mala cuando ésta se presenta en los medios de comunicación más populares, y con ello ayuden a sus estudiantes a hacer lo mismo (Barnett, Wagner, Gatling, Anderson, y Kafka, 2006, pág. 190). 
${ }^{4}$ La ficción o confección derivativa es también denominada fanmade y puede ser fanfic/relato, fanart/pintura, fansong/ canción, fanfilm/película, viddin/video, fanzinel revista, ezine/revista digital, fanadvertisings/anuncio, fandub/doblaje amateur, fansite/página web, fansub/ subtitulaje amateur, scanlation/traducción y edición amateur de cómic o libro, merchandising pirata y cosplay/disfraz. Ejemplos

de este fenómeno del fanmade pueden rastrearse históricamente, y el caso más antiguo es precisamente el ciclo homérico, con la proliferación de poemas creados como extensiones y sátiras de la llíada y la Odisea. Así, cada historia cuyo atractivo fascina al gran público ha sido sujeta a emulaciones, homenajes, adaptaciones e incluso plagios, por parte de sus seguidores, hasta la época actual. Y al emular la obra se han convertido en autores por derecho propio, pues no existe, al menos en la

CF, la dualidad entre el seguidor y el profesional, independientemente de sus posibles atentados al derecho de autor
Según estos investigadores, es necesario procurar que los futuros profesores de ciencias y de educación básica en general aborden el estudio de la sci-fi y de la ciencia ficción, desde la perspectiva de su plausibilidad científica. Lo que requiere, por un lado, un acucioso conocimiento de la ciencia involucrada, a la vez que un disfrute de los productos del género.

\section{Estrategia para el uso pedagógico de un ícono de la sci-fi: Godzilla}

En 2017 se estrenó la película 32 de la franquicia Godzilla (Shizuno y Seshita, 2017), y con toda la parafernalia asociada al monstruo más icónico del siglo xx es posible buscar provecho de los apetitos ficcionales despertados en la mente de los alumnos. Baste teclear el descriptor "Godzilla" en cualquier buscador, para conocer el bestiario de la saga. Internet se convierte entonces en una fuente de producción y conocimiento para el fandom, porque cuando a un fan le interesa un héroe, un ícono, un elemento o una trama ficcional, se despierta su apetito por conocerlo todo: génesis, autor, historia, correlatos, atributos, e incluso puede llegar a desarrollar algún tipo de ficción derivativa. A cualquier maestro le encantaría contar con alumnos capaces de crear fanmades ${ }^{4}$ como los que se pueden encontrar con toda facilidad en línea, y que son equiparables a los trabajos de los naturalistas en la era de las exploraciones geográficas y naturales del siglo XIX.

Hay algunas preguntas que el docente de educación primaria puede explorar con este ícono: ¿cuál es el animal más pesado que ha existido en tierra? Dado que la respuesta es la ballena azul (entre 25 y 34 metros de largo, y cuyo peso varía entre las 200 y 300 toneladas), un animal que lucha contra la gravedad en un medio acuático, conviene preguntar: ¿cuál es el animal más pesado en tierra? Existen varios candidatos: el Amphicoelias -81 a 135 toneladas. RuizOmeñaca, 2005, pág. 17-, el titanosaurio y el Diplodocus -81 a 135 toneladas (Ruiz-Omeñaca, 2005)-, mientras que, en la actualidad, el más pesado es el elefante africano, con sólo diez toneladas. Todos ellos son cuadrúpedos, pero Godzilla camina en dos patas. La pregunta siguiente sería: ¿cuál es el bípedo más pesado? El Therizinosaurus, que llegaba a alcanzar las seis toneladas (Zanno y Makovickyhe, 2013, pág. 2). La dinámica del peso y la configuración anatómica impide que un bípedo alcance gran tamaño, mientras que un cuadrúpedo sí puede conseguirlo, como se ve en los ejemplos citados. Un bípedo no podría sostener su cuerpo, como puede constatarse con el ave más pesada del mundo, el avestruz, que sólo alcanza 180 kilos y que, por supuesto, no vuela. ¿Y el más pesado en el aire? El Quetzalcoatlus entre 200 y 250 kilos (Atanassov y Strauss, 2002).

Otra pregunta relevante para los niños es la de las patas, si el bípedo pesa más de 20 toneladas, como es el caso de Godzilla, ¿de qué ancho deben ser sus extremidades para que no se derrumbe? Se puede traer a colación el grueso de 


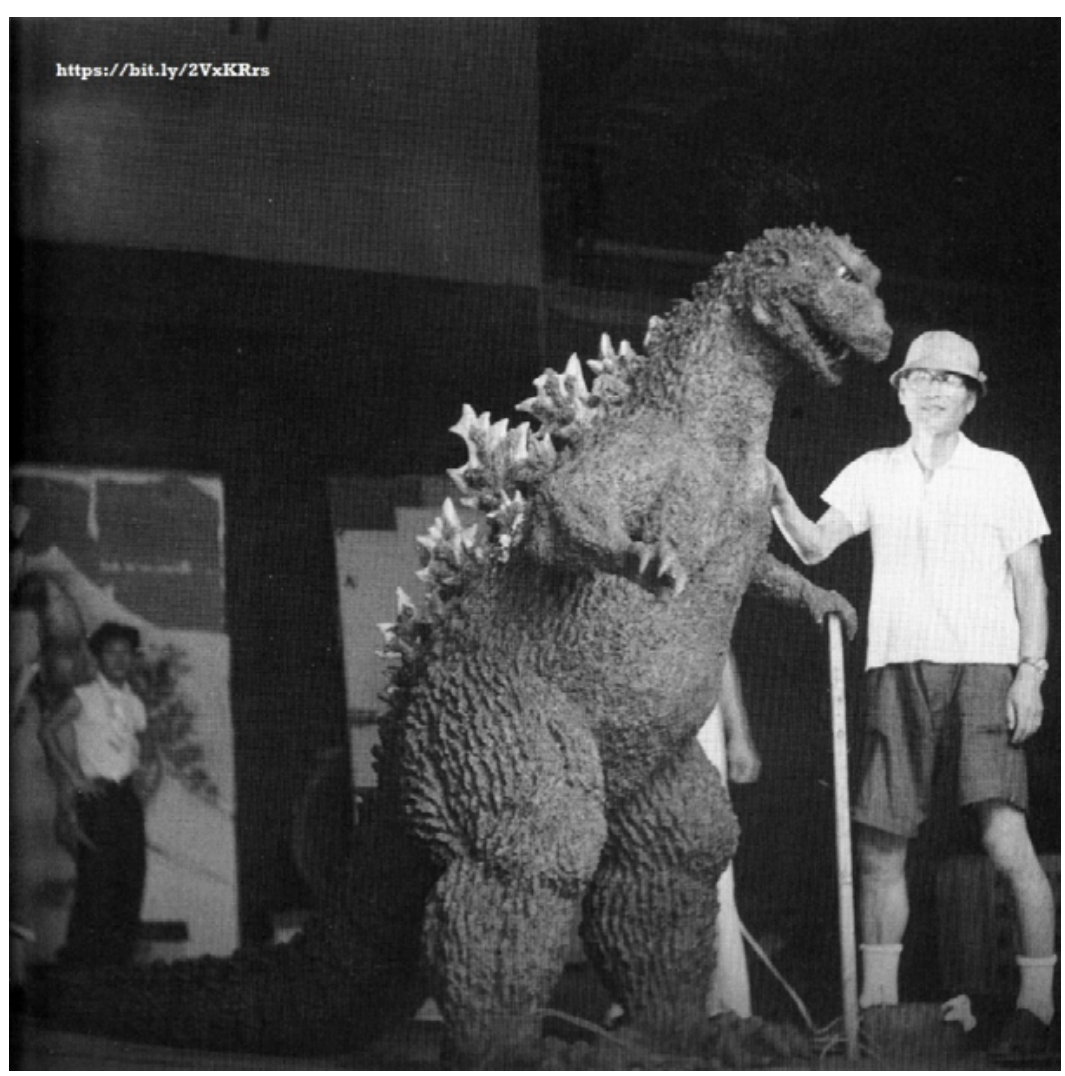

las patas en elefantes, rinocerontes, así como las del Argentavis magnificens y del Aepyornis maximus, aves que coexistieron con el hombre en la antigüedad (el primero, con un peso de 65 a 120 kilos, según Palmqvist y Vizcaíno, 2003, pág. 379; y el segundo, 418 a 457 kilos, de acuerdo con Amadon, 1947, pág. 163) y cuyas extremidades, podría suponerse, serían tan gruesas como la cintura de un ser humano (ver imagen 2).

En las representaciones japonesas de esta bestia ficcional, las patas parecen ser lo suficientemente anchas como para sostener el peso de 120 toneladas en tierra (una idea equivocada que preocupa a los biólogos), cosa que no ocurría con el Godzilla del film de Roland Emmerich (1998), cuyas delgadas patas provocaban la risa de los expertos. Sin embargo, ambos godzillas contravienen las leyes de la física y las matemáticas. Porque de acuerdo con críticos como

Imagen 2. Fotografía del traje prototipo usado para el filme Godzilla (1954). Aunque es obvio que se hizo para adaptarse al ser humano que actuaba como la bestia, el grosor de las patas es más certero que otras versiones digitales.

5 Enunciada por Galileo en el siglo XVI, según la cual en un determinado campo gravitatorio hay un tamaño máximo para cualquier cuerpo. Esto significa que por grande que sea una hormiga, sus patas, aunque sean proporcionales al tamaño, no podrían aguantar el peso en un planeta con una fuerza de gravedad como la Tierra (Sandri, 2012).
José María Sorando y Piergiorgio M. Sandri, existe una imposibilidad real de supervivencia de pesadillas cinematográficas tales como arañas, hormigas, cocodrilos, lagartijas y demás bestias gigantes, debido a la ley cuadrado-cúbica. ${ }^{5}$

Lo anterior descalifica la existencia verosímil de cualquier bestia masiva sobre la superficie terrestre. Lo que incluye a cualquier gigante literario, como Gulliver, los titanes y atlantes clásicos, los titanes de Hajime Isayama (2009), los ultramanes (1966), o robots como los de El gigante de hierro (1999) y Titanes del Pacífico (2013). El maestro que conduzca una crítica sobre estas bestias puede inquirir a los alumnos sobre la posibilidad de que un humano sea mayor al promedio, lo que los lleva a darse cuenta de que, a mayor peso y altura, mayores problemas de salud en individuos reales.

Hay otra perspectiva fisiológica para tratar en clase el tema de Godzilla. Un aspecto de los más Ilamativos dentro de los temas de la Otredad en la ciencia ficción es el mutante. En su concepción clásica, el mutante es un ser tocado por una deidad o afectado por un influjo, sortilegio o maldición, que se transforma en algo distinto a lo que era en su nacimiento. Así tenemos a Casandra con su presciencia, a Tiresias el transexual, Midas y su toque de oro, Cenicienta con sus donativos, o Gregorio Samsa y su metamorfosis. A partir de la era atómica, estas metamorfosis se operan como efecto de la contaminación radiactiva. Las preguntas que podemos hacer a los alumnos giran en torno a, por ejemplo, por qué Japón se encuentra tan obsesionado con las bombas atómicas, las 
catástrofes inescrutables y las mutaciones. Evidentemente, su historia, al ser el único país atacado por bombas atómicas, cuyos efectos aún sufre y que forman parte del imaginario social, dicta este desarrollo ficcional en su múltiple presencia como desastre o amenaza apocalíptica en filmes, mangas y animes, así como en las variadas formas mutantes de sus ficciones. Godzilla, como ícono moderno, representa y prefigura los temores nacionales a las bombas atómicas, por lo que es la personificación de la amenaza nuclear.

En el terreno científico, es conveniente preguntar a los alumnos cuáles son los efectos reales, benéficos y perniciosos de la radiactividad (no exclusivamente la artificial de las bombas, sino en todas sus variantes). ${ }^{6}$ Puede entenderse que la radiación es parte del ecosistema y afecta a los organismos vivos. Curiosamente, las mutaciones que han dado paso a la evolución de las especies pueden en parte ser atribuidas a la radiactividad y la selección natural, según lo cual las mutaciones aleatorias producidas por la radiactividad natural en algunos casos han sido neutrales y no han afectado la adaptabilidad y reproducción del individuo y, por lo tanto, han pasado de generación en generación. Asimismo, los organismos mutados tienen características que, por ser más óptimas, garantizan una mejor sobrevivencia en determinado ambiente. La mutación, de ser positiva, se produce a lo largo de múltiples generaciones, no en una sola procreación, y mucho menos en el sujeto afectado. Asimismo, en el caso de la radiactividad artificial producida por el hombre, el conocimiento médico es más que imprescindible para entender estos procesos, pues, al igual que cualquier otra medicina, el potencial curador va aparejado de efectos secundarios conocidos, en ambientes controlados. Por lo tanto, una exposición accidental a la radiación conduce a efectos médicos devastadores más que a superpoderes, lo que acaba con la verosimilitud de varios personajes de Marvel Comics, como Spiderman. Sin embargo, una búsqueda simple puede informar a los alumnos sobre todas las aplicaciones que la radiación tiene en la vida moderna, lo que les permite hallar una frontera nítida entre realidad y ficción.

Por tanto, sólo en la ficción la radioactividad produce efectos extraordinarios

${ }^{6}$ Soledad Esteban Santos y Javier PérezEsteban responden que la radiactividad consiste en que ciertos materiales espontáneamente emiten unas radiaciones de gran

energía. En un principio este hecho se detectó en materiales que existían en la naturaleza (radiactividad natural). No obstante, con el tiempo se ha conseguido provocar o inducir procesos radiactivos, por lo que este fenómeno se produce de forma artificial (radiactividad artificial) y aporta ventajas inmediatas al individuo. Como novedad o novum, en el caso de Godzilla, la radiactividad es más una advertencia de carácter social e histórico contra los usos desmedidos de la ciencia, más que el desarrollo de una hipótesis científica. En el plano de la ficción, esta idea se apega a la especulación sobre qué pasaría si los efectos perniciosos de la radiación nuclear provocaran el crecimiento desmedido de animales ordinarios e inocuos para la raza humana.

\section{Preservación del gusto infantil}

Al usar la ficción como motivación para el aprendizaje de las ciencias, cabe advertir la inconveniencia de destruir el gusto de los niños por estos productos. Diversos estudios demuestran que los jóvenes lectores se aproximan a la ficción por razones psicológicas difíciles de desentrañar, pero en lo general, sus gustos radican en objetivos diversos a los que los adultos consideramos deseables o adecuados, 
y que no siempre perciben las tramas y a los personajes en la forma como lo hacemos con nuestra racionalidad adulta (Bettelheim, 2006; Boimare, 1998; Propp, 1971). Ejemplo de ello es la preferencia de niños y niñas por identificarse con el antagonista de la ficción, en lugar del héroe, o con personajes que no se corresponden con su género. Dejando de lado esta cuestión, es claro que a nadie le gusta que le destrocen el objeto de su pasión para explicárselo, pero si el análisis se hace entre pares de la misma inclinación, entonces se producen efectos que no tienen nada que ver con la ficción, como el crear lazos de amistad o fundar iniciativas y proyectos que promueven evidencias difíciles de alcanzar en la educación regular. Ejemplo de ello es el fandom (por género o especializado en una sola ficción), que, como ya se ha mencionado, engendra fanmades de todo tipo, lo que implica que los fans aprenden a ser escritores, traductores, editores, músicos, fotógrafos, diseñadores, camarógrafos, programadores, ingenieros de sonido y administradores o anfitriones de sitios web ( $y$, también, distribuidores piratas, algo contra lo que se les debe precaver), y ya se han dado casos de profesionalización a partir de una pasión, como sucede de antiguo en el mundo del deporte y del arte.

Por tanto, y en el afán de aprovechar el potencial de la ciencia ficción en la enseñanza de la ciencia, se sugiere iniciar por la detección de la ficción o el ciclo de moda entre el alumnado (series con un elemento argumental común, como la saga inspirada en The Avengers de Stan Lee y Jack Kirby, 1963). Una vez detectado, el maestro habrá de preocuparse por conocer, incluso al nivel de la mera referencia, el argumento y sus elementos más significativos. A continuación, deberá elegir el fragmento, la escena, el capítulo o el afiche que tenga el potencial de generar la pregunta inicial de la investigación que se ha de procurar como motivo de aprendizaje. Y mediante la negociación verbal, alcanzar la pregunta motivo del estudio, de preferencia, sugerida por el grupo. A esto, que llamamos generación de ambientes de aprendizaje, le debe suceder el permitir que los alumnos realicen acciones desde el aprendizaje colaborativo, en la confección de cualquier estrategia de abordaje del conocimiento (proyecto, estudio de caso, exposición, basado en problemas, simulación o in situ). Obviamente la evidencia o el producto será siempre aquello que refleje el aprendizaje del conocimiento o la concepción correcta de la ciencia, sin destruir la ficción.

\section{Conclusión}

Los maestros vemos con preocupación el uso desmedido y la afición de los alumnos de los diversos recursos de internet, los cuales, en gran medida, se corresponden con una enorme pérdida de tiempo, dinero y energías, sin efectos positivos para su educación. Pero hacemos poco para paliar esta situación, con actividades más cercanas a la formación deseada.

Es fama que Alejandro Magno era gran admirador de los poemas homéricos (Arriano, 1982, libro I, cap. xII), al grado de envidiar la suerte de Aquiles por contar 
con Homero como poeta de sus hazañas. La llíada y la Odisea son textos que, aparte de su valor cultural y artístico, hablan sobre temas consideramos poco adecuados para la juventud (violencia, robo, secuestro, violación y asesinato), a la par que ensalza valores deseados (amistad, compasión y sacrificio). En tal sentido, las ficciones modernas se aproximan a los poemas clásicos y romances medievales, con su cuota de temas poco edificantes para los más jóvenes. Durante diez siglos, sin embargo, los poemas homéricos fueron el libro de texto de griegos y romanos en la enseñanza de las primeras letras. También se sabe que en cada hazaña que el conquistador macedonio abordaba, tenía en mente la emulación de Aquiles, por lo que no era tan diferente anímicamente de nuestros niños y niñas que hacen cosplay en sus fiestas infantiles, pues lo que los mueve es una estructura ficcional que se corresponde con su personalidad y que resuena con su psique. Aprovechar este deseo de emulación, este gusto en beneficio de un objetivo educativo, es, por tanto, la base de una estrategia de aprendizaje coherente con el mundo moderno. Algo que también se sabe es que, en su afán de emular a su héroe, Alejandro Magno bebió de las enseñanzas de sus maestros con el fin de saberlo todo y alcanzar a su ideal (aprendió medicina para cuidar de las heridas de sus amigos, tal como hacía Aquiles). Es decir, su camino hacia la ciencia pasó por la ficción primero. También se reconoce que más tarde detectó cuántos errores de percepción y de interpretación de la realidad había tanto en los poemas como en los maestros que lo educaron, pero esa es una consecuencia obligada del aprendizaje y el desarrollo personal.

Nuestros niños, por lo tanto, pueden iniciar su camino hacia el conocimiento científico, hacia el uso de los métodos y el pensamiento científico, mediante su afición por la sci-fi omnipresente en la cultura moderna, como parte de su trayecto lector individual; pero deben hacerlo también con ayuda de la mediación escolar y del maestro, en un esfuerzo coordinado para detectar la forma cómo la ficción norma su pensamiento. Porque, a pesar de la escuela, los niños aprenderán de la buena o mala ciencia expresada en los relatos que forman parte de la mitología moderna.

\section{Referencias}

* Amadon, D. (jul.-ag. de 1947). An Estimated Weight of the Largest Known Bird. The Condor, 49(4), 159-164. Dol: https://doi.org/10.2307/1364110.

- Arranz, A. (2014). Godzilla is back [infografía]. The Review supplement. South China Morning Post Publishers LTD, Hong Kong. Recuperado de: https://i.pinimg.com/ originals/ec/43/de/ec43de9f02a5a834fdd5b4ad0a6a74a3.jpg. 
* Atanassov, M.y Strauss, R. E. (2002). How much did Archaeopteryxand Quetzalcoatlus weight? Mass estimation by multivariate analysis of bone dimension [póster]. Society of Vertebrate Paleontology annual meeting.

* Barnett, M., Wagner, H., Gatling, A., Anderson, J., y Kafka, A. (2006). The Impact of Science Fiction Film on Student Understanding. Journal of Science Education and Technology, 15(2), 179-191. Dol: https://doi.org/10.1007/s10956-006-9001-y.

Bettelheim, B. (2006). Psicoanálisis de los cuentos de hadas. Barcelona: Crítica.

Boimare, S. (1998). El niño y el miedo de aprender. México: SEP-FCE.

* Eco, U. (1984). Apocalípticos e integrados. España: Lumen.

* Esteban Santos, S., y Pérez-Esteban, J. (2012). Estudiando el fenómeno de la radiactividad a través de noticias de prensa: el caso del espía ruso envenenado. Revista Eureka sobre Enseñanza y Divulgación de las Ciencias, 9(2), 294-306. DOI: https://doi.org/10498/14737.

* National Academy of Sciences (2016). The Science \& Entertainment Exchange. Recuperado de: http://www.scienceandentertainmentexchange.org/about.

* Palmqvist, P., y Vizcaíno, S. F. (30 de septiembre de 2003). Ecological and reproductive constraints of body size in the gigantic Argentavis magnificens (Aves, Theratornithidae) from the Miocene of Argentina. Ameghiniana. Revista de la Asociación Paleontológica Argentina, 40(3), 379-385.

- Pimentel, L. A. (1993). Tematología y transtextualidad. Nueva Revista de Filología Hispánica, 41(1), 215-229. DOl: http://dx.doi.org/10.24201/nrfh.v41i1.931.

* Pringle, D. (1991). Ciencia-ficción. Las 100 mejores novelas: una selección de lengua inglesa, 1949-1984. (M. Figueroa, Trad.) México: Minotauro/Hermes.

* Propp, V. (1971). Morfología del cuento. Madrid: Fundamentos.

* Ruiz-Omeñaca, J. I. (2005). Nuestros fósiles: Los dinosaurios saurópodos. Aragonia, Boletín Interno de la Sociedad de Amigos del Museo Paleontológico de la Universidad de Zaragoza, 10, 24-30. Recuperado de: http://aragosaurus.com/secciones/ publicaciones/artic/Ruiz-Ome\%C3\%B1aca 2005.pdf.

* Sandri, P. M. (9 de marzo de 2012). Cuando cine y ciencia no coinciden. La Vanguardia [sección Vida]. Recuperado de: http://www.lavanguardia.com/estilosde-vida/20120127/54245800802/cuando-cine-y-ciencia-no-coinciden.html.

* Sorando Muzás, J. M. (junio de 2007). Gazapos matemáticos en el cine y en la televisión. Suma, 55, 117-125. Recuperado de: http://matematicasmundo.ftp. catedu.es/CINE/55cinemateca.pdf.

- Suvin, D. (1984). Metamorfosis de la ciencia ficción. Sobre la poética y la historia de un género literario (2a ed., F. Patán López, Trad.) Mexico: FCE.

* Zanno, L. E., y Makovickyhe, P. J. (Enero de 2013). No evidence for directional evolution of body mass in herbivorous theropod dinosaurs. Proceedings of the Royal Society B: Biological Sciences, 280(1751), 1-8. Dol: https://doi.org/10.1098/ rspb.2012.2526. 


\section{Películas y cómics citados}

* Bird, Bread (director). (1999). El gigante de hierro [película, basada en la novela The Iron Man (1968) de Ted Hughes].

Del Toro, Guillermo (director). (2013). Titanes del Pacífico [película].

* Emmerich, Roland (director). (1998). Godzilla [película].

* Isayama, Hajime. (2012). Ataque a los titanes. España: Norma.

* Kubrick, Stanley (director). (1968). 2001: A Space Odyssey [película, guión de Stanley Kubrick y Arthur C. Clarke].

* Niccol, Andrew (director). (1997). Gattaca [película].

* Nolan, Christopher (director). (2014). Interestelar [película].

* Scott, Ridley (director). (2015) The Martian [película, basada en la novela de Andy Weir (1911)].

Shizuno, Kobun, y Hiroyuki Seshita (director). (2017). Godzilla [película].

- TOHO animation. (15 de agosto de 2017). Godzilla. Recuperado de: https://youtu. be/16K-M2IzTWW.

- Tsuburaya, E. (director). (1966). Ultraman [película].

- Villeneuve, Denis (director). (2016). La llegada [película, basada en el cuento "Story of Your Life" (1998) de Ted Chiang].

Zemeckis, Robert (director). (1997). Contacto [película, basada en la novela de Carl Sagan de 1985].

\section{Proyectos y compañías asesorados por The Science and Entertainment Exchange}

The Exchange afirma en su sitio web que el asesoramente que se brinda a los solicitantes no certifica la certeza del producto, y que no comparte las opiniones vertidas en el mismo.

Compañías productoras: Blind Wink Productions, Blue Sky Studios, Chris Morgan Production S, Film 44, Gk Films, Junction Entertainment, Kurtzman Orci Paper Products, Marvel Studios, Original Film, Scott Free Productions.

Películas: Tron: Legacy, Priest, Mental, Green Lantern, Battleship, Contagion, Prometheus, Avengers, Thor, Doctor Strange, Apollo 18, Blackhat, Ant-Man.

Televisión: House, The Big Bang Theory, Criminal Minds, Covert Affairs, The Good Wife, Castle, Fringe, Bones, Heroes, Terra Nova, Lie to Me, Known Universe, I, Predator, Caprica, The Lost Future, Eureka! 


\section{Cómo citar este artículo}

* Sánchez Arce, Claudia (2019). Aprendiendo ciencia con Godzilla. Revista Digital Universitaria (RDU). Vol. 20, núm. 3 mayo-junio. Dol: http://doi.org/10.22201/ codeic.16076079e.2019.v20n3.a7.

Recepción: 22/03/17 Aprobación: 08/04/19 